\title{
HISTORIA DE EUROPA. EL ADVENIMIENTO DE LA DEMOCRACIA
}

\section{HISTORY OF EUROPE. THE ADVENT OF DEMOCRACY}

\author{
José Miguel Delgado Idarreta \\ Universidad de La Rioja
}

\begin{abstract}
Recensión de / Review of: Manuel Sales y Ferré, Historia de Europa. El advenimiento de la democracia, Estudio preliminar Gonzalo Capellán de Miguel, Urgoiti editores, Pamplona, 2020, Pág C del estudio, 130 del trabajo
\end{abstract}

Palabras clave: Sales y Ferré, Europa, democracia, ciencia, sociología

Key Words: Sales y Ferré, Europe, democracy, science, sociology

\section{MANUEL SALES Y FERRÉ, UN HISTORIADOR EN EL SIGLO DE LA CIENCIA}

El profesor Gonzalo Capellán de Miguel de la Universidad de La Rioja ha llevado a cabo el estudio preliminar de la obra de Manuel Sales y Ferré, bajo el título genérico de Historia de Europa. El advenimiento de la democracia, lo que supone tener en nuestras manos dos trabajos completos y complementarios ambos.

En el caso del estudio preliminar que se ha titulado "Manuel Sales y Ferré, un historiador en el siglo de la ciencia" se nos presenta a Sales y Ferré, en primer lugar, como quien "es probablemente uno de los más destacados intelectuales de la España de finales del siglo XIX" en palabras del profesor Capellán, a la vez que añade que ha sido uno de los que menor atención ha recibido por parte de la historiografia. Dos afirmaciones que nos ponen en el punto de mira de lo que representó en su tiempo como historiador y como sociólogo, al ocupar la primera cátedra de Sociología en la universidad española allá por 1899. Todo ello sin obviar la huella del krausismo en su quehacer cotidiano. Tampoco debe olvidarse su trayectoria profesional tanto en la Universidad de Madrid, como luego en la Universidad de Sevilla "como catedrático de Geografia Histórica y de Historia Universal", donde desarrolló una ingente labor como investigador en "la arqueología, la prehistoria, la etnografia, la mitología..." y resaltando, a su vez, su labor difusora en la Biblioteca Científico-Literaria -de la que saldrian obras tan influyentes en la época como la traducción de los Estudios politicos y sociales de Herbet Spencer- o en el Ateneo Hispalense. Posteriormente volvería a Madrid haciéndose cargo de la ya mencionada cátedra de Sociología.

En ese amplio estudio introductorio que Capellán pone encima de la mesa respecto al quehacer de Sales y Ferré destaca su labor no solo académica, sino también por "presentar grandes síntesis con fines educativos y divulgadores como su Historia general", reeditada en numerosas ocasiones entre 1884 y 1923. En esta línea investigadora y de difusión se acerca a la Historia de Europa desde la revolución francesa hasta nuestros días iniciada por Emilio Castelar en 1895. 
Obra que se titularía finalmente de la mano de Sales y Ferré Historia de Europa en el siglo XIX en los volúmenes finales (V y VI) publicados en 1900 y 1901. De sus manos, puede decirse, que salió y aportó las líneas de futuro en el quehacer histórico.

Partiendo de todo lo anterior el profesor Capellán se introduce en la segunda parte del estudio introductorio en la formación intelectual del personaje destacando la impronta del krausismo en su realidad, llamando la atención en la concepción de la historia, no como algo lineal, sino como una perspectiva "abrupta y sinuosa", lo que tampoco significa "una idea de progreso, de mejora paulatina y gradual con el paso del tiempo" siguiendo la línea de la filosofia moderna, que encumbra en Bacon, Bossuet, Turgot, Fichte, Hegel o Saint-Simon, sino en lo ya señalado por Castelar en referencia a Condorcet. Así será la sociabilidad del individuo, la que construirá la familia, el municipio, la provincia, la nación y la federación de naciones "hasta culminar en la alianza de la Humanidad". Un ideal cosmopolita hacia el que se avanzaba desde una articulación del territorio europeo, ya mostrado por Kause o por Víctor Hugo en 1848 en su defensa de la creación de los Estados Unidos de Europa como punto de arranque para el futuro de la humanidad. De ahí a interesarse por la antropología solo hay un paso, que se complementa con el entonces evidente avance de las ciencias geográfico-históricas, con "la ampliación del horizonte de ciencias como la Geografia, la Etnología, la Etnografia, y la Paleontología humana", que marcan la pluridisciplinar concepción de la historia por parte de Sales y Ferré.

El trabajo de Gonzalo Capellán nos adentrará posteriormente en la etapa sevillana donde desde su Universidad facilitará el contacto con Federico de Castro, Rector de la Universidad, y le permitirá fomentar la Biblioteca CientíficoLiteraria en lo que se define como "una aventura editorial", por una parte, y, por otra, en el contacto y colaboración con Siro García del Mazo, vicepresidente del Ateneo Hispalense, que le llevó a colaborar con el diario democrático La Discusión, en las aportaciones a las obras en torno a la civilización europea, que saldrá "triunfante de la actual crisis, que en realidad es un sintoma de evolución" y a la redacción entre 1889 y 1897 del pionero tratado de Sociología, cuya primera parte denominó Estudios de sociología, evolución social y politica, donde, entre otras cuestiones, aborda "la constitución social de los más diversos pueblos antiguos". Dando, en este momento, finalizada su etapa sevillana para volver a Madrid.

En esta etapa final entrará en la polémica en torno a los nuevos planes de estudio y la Filosofia de la Historia al iniciarse el siglo XX, anunciándose así el peso creciente que las nuevas ciencias sociales iban a tener, en muchos casos desprendiéndose progresivamente del tronco común del Derecho, como sucederá con la Ciencia política. Aportó también sus conocimientos en torno a Sanz del Río, escribiendo multitud de notas en los márgenes de los libros del krausista, que señala el profesor Capellán fue "el libro mas estimado por él de todos los de su biblioteca" como testimonió Feliciano Candau ya en 1911. Es entonces cuando aborda la Historia de Europa en el siglo XIX de Castelar y que a su fallecimiento aprovecha el original escrito por el gran retórico un monumental proyecto historiográfico, tanto por su alcance como por su calidad formal y estética. Asume, junto a Siro García del Mazo y Salvador Calderón, la redacción y edición 
de los dos volúmenes finales, el V y el VI, cuya conclusión -afirma Capellánreproduce "un texto tomado del Tratado de Sociología".

Para cerrar este análisis se explicará la sonada polémica en torno a la decadencia de España, que tendrá gran eco en la prensa e incluso en el Congreso de los Diputados. No olvidemos que estamos en los finales del siglo XIX cuando se perdió Cuba, Puerto Rico, Filipinas y las islas del Pacífico. Debate que se desarrolló en el Ateneo de Madrid en diciembre de 1901, presidido por Segismundo Moret y ocupando la mesa presidencial, entre otros, el Conde de Romanones, como ministro de Instrucción Pública. Polémica en la que Sales y Ferré, que siempre se había centrado "en sus investigaciones y difusión científica y cultural" y no en el juego político, pues nunca albergó esperanzas en dicho terreno, fue malentendido, generando alguna “contrariedad" y "disgusto" en el Sr. Ministro. Enfado que se explica ante las palabras del sociólogo que aseguró que "la causa de la agonía de España obedece a que las clases ejecutoras son excelentes y las clases directoras son deplorables". Como explica Capellán, "en el contexto del régimen monárquico-constitucional que daba forma al Estado de la Restauración" afirmar que la decadencia actual de España encontraba en "nefandas tradiciones" heredadas desde el siglo XVI y "la degeneración de todas las estirpes regias" fue inmediatamente sentido como un ataque directo a la monarquía.

La obra de Sales y Ferré aborda en sus últimas páginas la Historia de Japón, así que el profesor Capellán no puede dejar de aludir a la misma en su "Epílogo". Historia que se enmarca en el declarado universalismo del sociólogo. Será en la Real Academia de Ciencias Morales y Politicas, donde había ingresado en 1907 y donde planteó la rapidez con la que Japón se había asimilado a la civilización europea, versando su conferencia sobre "La transformación de Japón" sobre todo en esos años finales del siglo XIX que introducen a la nación insular asiática en el mundo contemporáneo, señalando que Japón se ha acomodado a la forma europea, pero no "al espíritu de la educación europea".

Esta parte del libro está bien complementada por una bibliografia selecta de Manuel Sales y Ferré desde 1874 hasta 1912, que permite al lector seguir el desarrollo del pensamiento del autor. Lo mismo que, al concluir los textos, nos encontraremos con un "Índice onomástico", que evidentemente, facilita la búsqueda por autores o personas que van apareciendo a lo largo de los textos del estudio y de la obra comentada.

\section{HISTORIA DE EUROPA. EL ADVENIMIENTO DE LA DEMOCRACIA}

Con estos mimbres no queda más que introducirnos en el pensamiento de Manuel Sales y Ferré en la segunda parte del ejemplar que nos ocupa y que lleva por título Historia de Europa. El advenimiento de la democracia, que a su vez está constituido por tres partes, como se explica en la nota de la edición y que son Civilización europea. Consideraciones acerca de su presente, su pasado y su porvenir, cuyo origen fue, según se añade en el libro presente, un discurso pronunciado en el Ateneo de Sevilla; el segundo corresponde "al capitulo XXXV de 'Síntesis y conclusión' que cerraba el tomo VI” de la obra que había iniciado Emilio Castelar y son las dos aportaciones más amplias; cerrando la compilación, un tercer texto, "De la civilización y su medida", que había sido editado en la revista dirigida José Lázaro Galdeano, La España Moderna. 
El primero de los trabajos sobre la civilización europea no puede iniciarse de otra manera que justificando el por qué de su abstracción al señalar la "Dolencia moral de nuestro tiempo" con palabras francamente duras, pero claras, denunciando las controversias que cada día se producen en los parlamentos y la prensa, con "la desesperación de los políticos de moralizar la administración; las quejas de los municipios empobrecidos y exhaustos por las desmedidas exacciones de una hacienda sin entrañas; ...; que les amenazan con nueva forma de esclavitud", sin olvidar a las asociaciones de obreros que "proclaman la total destrucción de lo existente", lo que le hace llamar la atención del "peligroso derrotero por donde caminan las sociedades europeas". Un dibujo de su presente verdaderamente problemático, y cuya descomposición le hará escribir más adelante, que se trata de una descomposición "próxima a la muerte". Sin duda alguna, un triste cuadro para introducirse en el tema, pero que refleja bien el pensamiento en ciertos ambientes intelectuales finiseculares.

Obviamente, las anteriores afirmaciones le llevan a Sales y Ferré en una segunda parte de su trabajo a analizar lo que denomina "Ley de desarrollo orgánico", indicando su nacimiento en el siglo XV con el Renacimiento, continuando el ciclo a lo largo de los siglos XVII y XVIII donde se va a producir un cambio radical, escribe, "una revolución" que llevará a una "nueva era de paz y de ventura; desde comienzos del presente, el perfeccionamiento continuo e indefinido del género humano". Así, de todas formas, no se avanza en línea recta como concepción abstracta del progreso, sino como "desarrollo orgánico o evolución" con periodos ascendentes y descendentes o de "progreso y retroceso". Así concluye este fragmento aseverando por una parte que "a la concepción abstracta del progreso en línea recta e indefinida, hay que sustituir la concepción experimental del desarrollo orgánico o evolución", y, por otra, sobre la base anterior debe entrarse en el debate de "si la descomposición de las actuales sociedades europeas es sintoma de muerte o de progresiva evolución".

Un tercer apartado abordará la cuestión de si “¿Es la inmoralidad actual sintoma de muerte o de evolución?", con lo que afirma que "los pueblos viven por su ideal". Un ideal que es "el alma de los pueblos", camino que trata de responder a esa cuestión de la muerte o el progreso evolutivo, con lo que precisará conocer los "Ideales de la civilización europea" destacando lo que denomina político-social y científico-religioso, para concluir analizando la dolencia moral como síntoma de la evolución. Por supuesto, opina, que lo político-social llevará de "la variedad nacional a la unidad internacional" y en lo que concierne a lo religioso-científico se avanzará "del subjetivismo metafísico a la razón práctica y universal". Así lo internacional, lo universal se convierten en ejes de su pensamiento que representa -como ya había enfatizado Capellán en el estudio previo- una superación del estrecho marco mental que constituía la idea dominante del Estado-nación.

Una cuarta cuestión se integrará en el debate que plantea, como es "La dirección que debemos imprimir a las fuerzas sociales para salvar la actual civilización". Ello le permite abordar una serie de cuestiones como cuáles son las causas de la decadencia moral de Europa, entre las que destaca la "pérdida de los ideales religiosos", la "instrucción", y la "centralización" y sus medios para combatirlas, por lo que resume que deben trocarse con el cultivo de la "ciencia como arte", la instrucción debe ser "real, total y orgánica" y debe racionalizarse a las sociedades "devolviendo la justa y legítima autonomía a las regiones y 
municipios" -asumiendo en este punto el ideal descentralizador de larga tradición en el progresismo español, reformulado en el organicismo krausista que hace del gobierno local y regional una fórmula de articulación territorial que armoniza las tensiones entre unidad y variedad-. Remedios, señala, que no son superiores a las fuerzas humanas y que sí facilitarán la "salvación de la civilización actual".

Antes de abordar la conclusión de su ideario mostrará el "ideal de este Ateneo (sevillano) y medios de realizarlo", trabajando por la verdad y practicando la instrucción real, total y orgánica, reitera, incluyendo la educación de la mujer. Por supuesto, ello exige sentimiento y voluntad y educar en la contemplación de la obra literaria y artística, así como observando las leyes "como ejemplo de nuestros semejantes y el respeto a la opinión pública", además de hacer renacer la vida municipal y regional "despertando su patriotismo". Lo que faculta la trascendencia social del Ateneo de Sevilla con toda su organización. Así concluirá que todas estas cuestiones servirán para crear el verdadero sentimiento que no consiste "ni en la ambición personal, triste supervivencia del salvajismo; ni a ese semillero de bastardas pasiones, que tantos estragos causan en la política", si todo ello se consuma desde la razón "ejecutándose por elevadas miras y nobles impulsos".

El segundo gran alegato lleva por título "Historia de Europa desde la Revolución Francesa hasta nuestros días. Síntesis y conclusión”, que habia iniciado Emilio Castelar y concluía Manuel Sales y Ferré. En este trabajo destaca la marcha de Europa y que "al abrirse el siglo décimo noveno, el aislamiento era la ley en Europa", llamando la atención sobre los creadores de riqueza y que no son los que la poseen, "el fabricante, el rentista o el banquero", sino el científico. Es esto lo que le permite mostrar muchos de los adelantos técnicos como el vapor, la electricidad, el perfeccionamiento de las industrias antiguas, los progresos en la agricultura, pero también "las explotaciones mineras o la conservación de las vías férreas", la construcción de barcos, o el desarrollo de la arquitectura, entre otros elementos. A la vez, también se fija en los aspectos políticos destacando la caída en 1830 de la monarquía de "tendencias absolutistas de Carlos X", y mostrando la Constitución de 1852, en el Segundo Imperio, pasando luego a Gran Bretaña Alemania, Italia o España, donde el absolutismo -y con él la doctrina del derecho divino de los reyes- también cayó al fallecer Fernando VII. Este hecho obligó a "Isabel II a confiar la defensa de sus derechos a los representantes del nuevo sistema", es decir, el liberal. La conclusión era obvia para Sales: "la nueva sociedad es más homogénea que la antigua". Todo ello para fijarse en la producción donde destaca que "hasta las clases sociales más bajas mejoran notablemente de posición". Con otras palabras, mejora lo económico y lo social.

Entra posteriormente en el tema de la soberanía donde explica que ésta en su origen "no reside en toda la colectividad, sino solamente en una parte de ella, y la ejerce la asamblea de representantes de los ricos con el rey". La evolución llevó a la aparición de la Constitución, con mayúscula, escribe, con lo que la soberanía "se transfiere a la colectividad". Es cierto que inicialmente la edad es un freno en el desarrollo del sufragio, pero poco a poco se irá ampliando "el derecho electoral", e, incluso, más tarde, se ampliará a todas las clases sociales. No puede olvidar la aparición del socialismo y se pregunta “¿triunfará?”, o, como alternativa, “¿prevalecerá entonces el individualismo? Todo ello sin soslayar que en el interior de las naciones se ha producido la transferencia "de la soberanía de 
los reyes a los pueblos" y la sustitución de la política por la economía, siendo "la consecuencia inmediata de ese predominio de la Economía Política", cuyo fin último será el que unas naciones se aproximen a otras "hasta unirse en federación continental". Esta secuencia representa en la evolución de estadios de las sociedades que establece la sociología histórica de Sales, el paso de la nación geocéntrica a la nación timocrática y de esta a la democrática, que había empezado a atisbarse en Europa desde 1848 y que a la altura en la que escribe (1901) se percibe como "el advenimiento de la democracia" como tendencia característica de sociedad que inaugura el siglo XX.

El último texto firmado por Manuel Sales y Ferré lleva por título "De la civilización y su medida" donde plantea, en primer lugar, qué debe entenderse por civilización. En su análisis las sociedades humanas atraviesan tres estadios el salvajismo inicial, la barbarie y la civilización, mostrando que uno de los datos de evolución de los dos primeros estadios, siguiendo a Mac-Lenan, pasa por "la invención de la vajilla" porque "el hombre es el único animal cocinero", punto de partida en la evolución hacia el bienestar de la vida. Y, en un segundo estadio, el trayecto hacia la civilización es la escritura que será, junto a la aparición de las ciudades, "el punto de partida de una nueva era en el desenvolvimiento de las sociedades humanas", con la defensa del territorio. Todo esto, concluye, es la visión histórica.

Un segundo momento de esta situación vendrá marcada por la institucionalización y el advenimiento de las costumbres que se transmiten de generación en generación, el surgimiento de la conciencia social, "base y sostén de la sociedad". Una tercera valoración es que "no son las letras, las artes ni la religión" las que muestran el grado de civilización, sino "la alteza de los ideales morales", con lo que concluye que la civilización se basa en "la organización social y política". A partir de aquí presentará el análisis de semejanzas y desemejanzas entre los diferentes grupos sociales y nacionales, lo que le lleva a preguntarse si las sociedades son capaces de un desarrollo continuo e indefinido. Cierra el estudio abordando la realidad de España, de la que afirma que ha sido "clara y sencilla", aunque concluye que la situación de su presente es triste, lo que le hace preguntarse si puede salvarse. Para ello pone en evidencia dos cuestiones como son el "sustituir al régimen actual una organización adecuada, ..., basada sobre los derechos fundamentales de la persona, la libertad y la igualdad" y en segundo lugar "enseñar y educar al individuo". Como colofón a estas líneas destaca la necesidad de la abnegación de "todos los patriotas españoles", para así alcanzar "el nivel de la moderna cultura", porque todo organismo vivo debe "desarrollarse, florecer y morir".

Tanto el trabajo introductorio del profesor Gonzalo Capellán como el estudio de Manuel Sales y Ferré dejan claro el camino histórico recorrido hacia la democracia, tal como dicta el propio título del ejemplar que tenemos en nuestras manos: cuál ha sido y es la Historia de Europa y cómo se desenvuelve -insistoese camino hacia la democracia.

Enviado el (Submission Date): 08/02/2021

Aceptado el (Acceptance Date): 15/04/2021 